Revue musicale OICRM

\title{
Présentation du numéro « Musique et exotisme en France au tournant du XXe siècle. Altérités recomposées »
}

\section{Sylvain Caron}

Volume 3, numéro 1, 2016

Musique et exotisme en France au tournant du XXe siècle. Altérités recomposées

URI : https://id.erudit.org/iderudit/1060118ar

DOI : https://doi.org/10.7202/1060118ar

Aller au sommaire du numéro

\section{Éditeur(s)}

OICRM

\section{ISSN}

2368-7061 (numérique)

Découvrir la revue

\section{Citer ce document}

Caron, S. (2016). Présentation du numéro « Musique et exotisme en France au tournant du XXe siècle. Altérités recomposées ». Revue musicale OICRM, 3(1), i-iii. https://doi.org/10.7202/1060118ar d'utilisation que vous pouvez consulter en ligne. 


\section{revue musicale oicrm}

Le site de la Revue musicale de l'Observatoire interdisciplinaire de création et recherche en musique

\section{Présentation du numéro «Musique et exotisme en France au tournant du $\mathrm{xx}^{\mathrm{e}}$ siècle. Altérités recomposées », vol. 3, nº 1 (2016) \\ Sylvain Caron}

Au cours des dernières années, le thème de l'exotisme et de l'orientalisme dans la musique et les beaux-arts a fait l'objet de nombreuses publications qui ont permis un renouvellement du regard et de la pensée sur le sujet. Après les positions assez tranchées de l'approche postcolonialiste de Saïd ([1978]1980), Born et Hesmondhalgh (2000) ont infléchi les réflexions autour du concept d'appropriation des formes symboliques. Plus récemment, Locke (2009) a insisté sur l'importance du réseau de significations qui apparaît dans le contexte d'une œuvre où

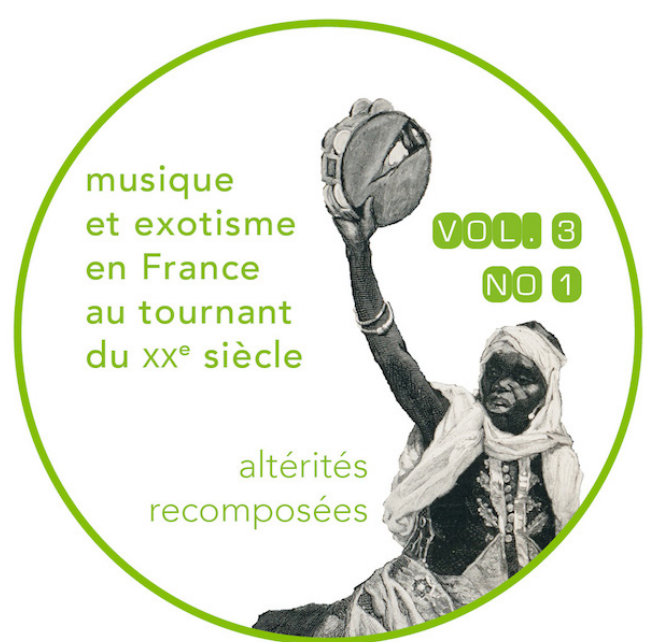
s'entremêlent texte et musique. Après des publications aussi riches, que peut-on écrire de nouveau?

Dans le cadre de ses activités de recherche, l'équipe «Musique française » de l'OICRM a collaboré avec le Musée des beaux-arts de Montréal (MBAM) lors d'une journée d'étude (29 avril 2015) autour de l'exposition Merveilles et mirages de l'orientalisme (31 janvier-31 mai 2015). Cette journée avait pour but de promouvoir la réflexion interdisciplinaire autour du thème de l'exposition. Quatre articles de cette publication proviennent de cette activité (Issiyeva, Duchesneau, Montiège et Caron). Il nous a semblé utile de joindre deux autres articles (Guerpin et Lazzaro) provenant de communications faites dans le cadre du colloque annuel de la Société de musique des universités canadiennes (MusCan, 2014). L'originalité de la contribution de l'équipe "Musique française " réside dans son approche interdisciplinaire entre musique et peinture, et dans une recomposition implicite du concept d'altérité. 
La revue s'ouvre par l'article de Martin Guerpin, qui remet en cause la tradition historiographique voulant que le jazz ait été automatiquement considéré comme exotique en France après la Première Guerre mondiale. Qu'est-ce qui est associé à l'Autre et qu'est-ce qui est le résultat d'une appropriation par le compositeur ? À un second degré, on observe que l'orientalisme français devient un objet culturel en soi, qui peut être " reçu " par une autre culture. Cette appropriation devient paradoxale lorsqu'elle retourne à sa culture d'origine après avoir subi les déformations d'un jeu de miroirs. Dans son article, Adalyat Issiyeva soutient que la réception de l'orientalisme français en Russie a provoqué une remise en cause de l'identité nationale chez les compositeurs russes. En fait, la déformation est liée à l'imitation, partagée entre la conformité à certains traits de l'original et la marque personnelle de l'artiste. Michel Duchesneau explique que Ravel était un habile imitateur, mais que son modèle de l'Orient se nourrit de sources littéraires où s'entremêlent imagination et connaissance objective. D'ailleurs, limiter une œuvre à sa seule dimension exotique serait réducteur. En se penchant sur cette question, Federico Lazzaro ajoute que dans les mélodies intitulées Chansons madécasses, Ravel considère davantage la référence à 1'Autre comme un déclencheur de son expression, un élément stimulant pour sa propre démarche comme compositeur. Le domaine de la mélodie est appréhendé de manière plus large par Sylvain Caron, qui prend appui sur ce genre pour situer l'avènement de la modernité musicale musicale dans le contexte de l'esthétique néopositiviste et des nouvelles théories de l'art énoncées par le peintre Maurice Denis. Enfin, pour conclure, Samuel Montiège apporte un éclairage original sur la musique telle que la voit le peintre Benjamin-Constant. Ayant collaboré de près à l'exposition, Montiège apporte des informations intéressantes non seulement en elles-mêmes, mais aussi en ce qu'elles ouvrent comme perspectives de recherches pour l'avenir.

Nous tenons enfin à remercier Madame Nathalie Bondil, directrice du Musée des beaux-arts de Montréal, pour le soutien qu'elle a apporté au projet. Elle nous a ouverts les portes de son musée pour la tenue de la journée d'étude et nous a conseillés pour sa conception scientifique. Les œuvres du Musée des beaux-arts présentes dans la revue ont été reproduites avec son aimable autorisation. Nous saluons avec enthousiasme cette belle collaboration interartistique.

Articles

L'exotisme en question. Le cas de la réception du jazz dans la musique savante française de l'entre-deux-guerres

1 Martin Guerpin

Chansons madécasses, modernisme et érotisme. Pour une écoute de Ravel au-delà de l'exotisme

16 Federico Lazzaro

Minarets et pagodes. L'Orient ravélien

56 Michel Duchesneau 
Dialogues of Cultures. French Musical Orientalism in Russia, "Artistic Truth," and Russian Musical Identity

71 Adalyat Issiyeva

Mélodie et orientalisme. De 1'évocation du merveilleux aux séductions de 1'avantgarde

93 Sylvain Caron

Benjamin-Constant et le lien à la musique. Un art entre citation et vision personnelle

115 Samuel Montiège

Notes DE TERRAIN

"Panel sur la critique musicale ", dans le cadre du colloque international Qu'en est-il du goût musical dans le monde au $X X t^{e}$ siècle ?, 28 février 2013, Faculté de musique, Université de Montréal, salle Serge-Garant

137 Caroline Marcoux-Gendron

La critique musicale : de la théorie à la pratique. Compte rendu de la journée d'étude, 13 mars 2015, Faculté de musique, Université de Montréal, salle Serge-Garant

147 Margalida Amengual Garí, Hubert Bolduc-Cloutier, Chloé Huvet et Marie-Pier Leduc 